J. Lake Sci.(湖泊科学), 2009, 21(4): 502-508

http://www.jlakes.org. E-mail: jlakes@niglas.ac.cn

(C2009 by Journal of Lake Sciences

\title{
太湖流域漕桥河小流域水环境容量估算及污染物削减分配*
}

\author{
张利民，刘 洋，孙卫红，边 博 \\ (江苏省环境科学研究院, 南京 210036)
}

摘 要: 太湖流域漕桥河区域水环境质量日益恶化，成为影响该区域可持续发展的主要问题之一，为此基于漕桥河小流域和 水质污染分段的特征，计算了研究区域的水环境容量和污染物削减量，提出河流污染分段控制和流域管理的水环境容量控制 模式, 建立河流氮磷污染控制的可操作性措施, 从而确定重点工程和措施实施的年度计划, 形成污染源年度削减方案, 可为 小流域污染控制管理提供科学依据.

关键词: 漕桥河; 小流域; 水质污染分段; 水环境容量; 削减方案; 太湖流域

\section{Estimation of water environmental capacity and allocation of pollutants reduction in a small watershed of Caoqiao River in Taihu Basin}

\author{
ZHANG Limin, LIU Yang, SUN Weihong \& BIAN Bo \\ (Jiangsu Provincial Academy of Environmental Science, Nanjing 210036, P.R.China)
}

\begin{abstract}
Pollution of Caoqiao River in Taihu Basin has become one of increasingly serious problems, which affects sustainable development of this region. A model was constructed based on the characteristics of the small watershed and segmentation of water polution, and applied to calculate the capacity of the water environment and the quantity of pollutants reduction. In this case, it is proposed a segment control pattern of river pollution and a water environmental capacity control pattern of watershed management. An operational plan for controlling nitrogen and phosphorus in rivers was established, thus the key project and the annual measurement were decided, and the annual reduction plan of pollution source was implemented, which has provided the scientific basis for better management of pollution control for small basin.
\end{abstract}

Keywords: Caoqiao River; small watershed; water pollution segmentation; water environmental capacity; reduction plans; Taihu Basin

太湖流域主要人湖河流处于平原河网地区，地势较低、工业密集、污染物人河量大、河流水环境质 量日益恶化，成为影响该流域环境和经济可持续发展的一个主要问题. 根据河道的水文特征、人河排污 口分布、设定目标水质和一定保证率下的设计流量，确定水环境容量模型 ${ }^{[1-2]}$, 计算河流的水环境容量, 确定污染物削减量, 是实现水环境功能区水质目标的主要手段，也是水污染总量控制的基础和核心 ${ }^{[3-5]}$. 目前, 关于河道水环境容量的研究较多 ${ }^{[6-8]}$, 河网动态水质模型的研究已有较大进展, 在上海等河网水系 中得到了广泛的应用 ${ }^{[9]}$. 漕桥河是太湖流域 15 条主要人湖河流之一，周边河流密布，水流缓慢，水体交 换速率低，河道污染物集聚量大，为典型小流域河网地区; 污染源以氮、磷污染为主，工业和居民沿河分 布，河段水质变化波动大，呈明显分段特征，研究起来比较复杂 ${ }^{[10]}$ ，在此条件下，根据漕桥河水系情况和 不同河段的水质特征，将漕桥河小流域分段进行水环境容量的测算，分段控制污染物允许排放量，以保 证漕桥河小流域的全线水质达标. 因此本文以漕桥河为例，基于实测数据进行水文模型的参数率定和验 证，提出小流域河网地区河流分段水环境容量计算方法，确定污染物的削减量，从而制定削减污染物的 重点工程措施, 为太湖流域水环境管理提供科学依据.

* 国家水体污染控制与治理科技重大专项(2008ZX07101-002)和江苏省科技厅太湖专项基金(基础研究计划)(BK2007744)联合 资助. 2008-10-27 收稿; 2008-12-23 收修改稿. 张利民, 男, 1966 年生, 博士, 研究员; E-mail: zhanglimin71@hotmail.com. 


\section{1 研究区域及计算方法}

\section{1 研究区域}

漕桥河位于江苏省宜兴市北部, 是太湖主要人湖河流之一，属于洮、滆、太水系，起源于滆湖，两岸 有37条主要河浜. 漕桥河与武宜运河交汇于上游的楝聚村, 与太滆运河交汇于下游的分水村. 根据《江苏 省地表水(环境)功能区划》, 漕桥河起始-终止位置, 武宜运河-太滆运河和滆湖口-武宜运河(闸口), 2010 和2020年水质目标均为 IV 和III类水. 全线从上游至下游依次设有徐家大塘、闸口(黄土桥)、漕桥、新塘桥、 分水桥和百渎港 6 个例行监测断面, 不同水期各断面水质类别统计分析结果表明, 漕桥河水质总氮、氨氮 为劣 $\mathrm{V}$ 类, 总磷为 $\mathrm{V}$ 类-劣 $\mathrm{V}$ 类, 高锰酸盐指数满足 $I V$ 类水质要求, 监测点位布置见图 1 .

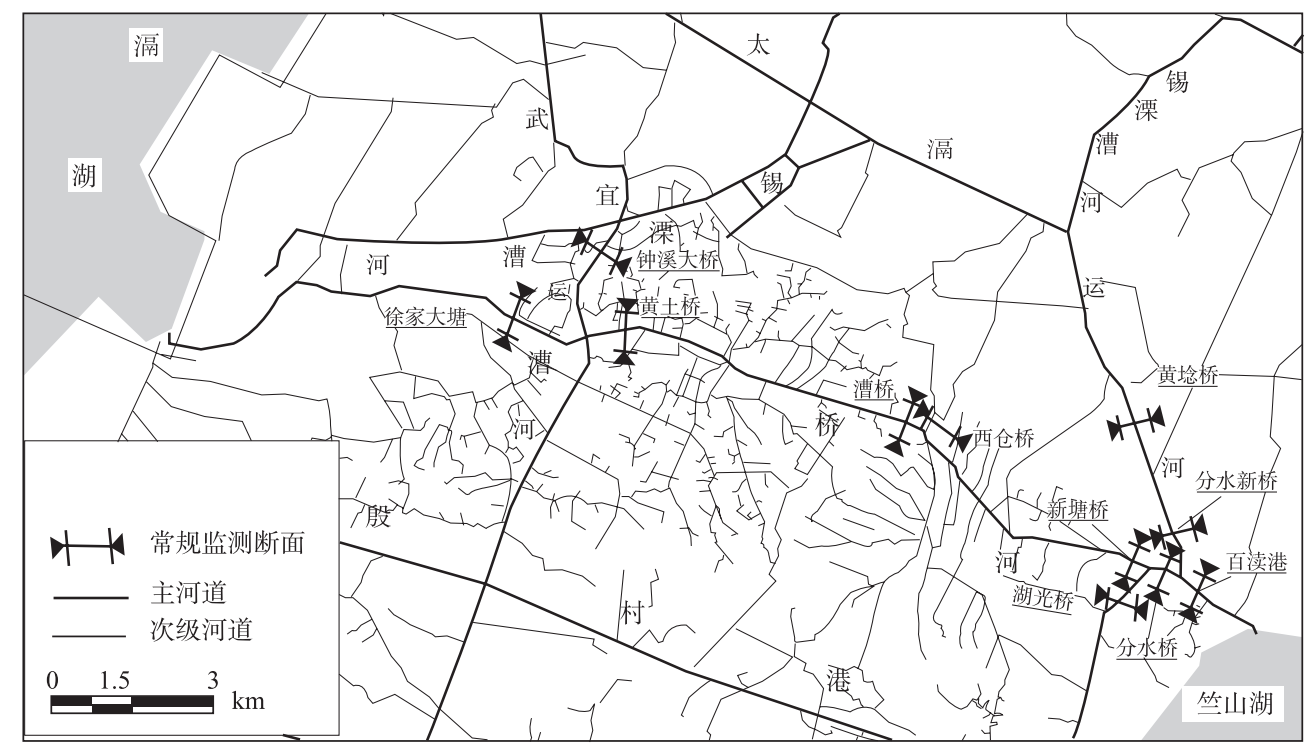

图1 漕桥河及主要水系水质常规监测点

Fig.1 Water quality monitoring point of Caoqiao River system

\section{2 河网(河道)区环境容量计算方法}

1.2.1 河网(河道)区环境容量计算 污染物进人河流水体后, 在污染物完全均匀混合的断面上, 污染物无 论是溶解态的、颗粒态的还是总浓度, 其值均可按节点平衡原理来推求. 断面完全混合的水环境容量计 算为零维问题视水体水质为完全均匀混合类型，即不考虑空间方向上的浓度梯度，应用公式1-5进行河 网环境容量的计算.

$$
W_{\text {纳污能力 }}=\sum_{j=1}^{n} \sum_{i=1}^{m} \alpha_{i j} \times W_{i j \text { 纳污能力 }}
$$

式中, $\alpha_{i j}$ 为不均匀系数; $\alpha_{i j} \in(0,1], \alpha_{i j}$ 取值参考相关研究结果 ${ }^{[11]}, W_{i j}$ 为计算中的最小空间计算单元和最小 时间计算单元. 计算中最小空间计算单元为河段(河段为两节点之间的河道); 最小时间计算单元为天.

$$
W_{\text {纳污能力 }}=Q_{0 i j}\left(C_{s i j}-C_{0 i j}\right)+K V_{i j} C_{s i j}
$$

式中, $C_{s i j}$ 为不同功能区相应水质标准下的浓度; $K$ 为水质降解系数; $V_{i j}$ 为不同功能区的水体体积; $Q_{0 i j}, C_{0 i j}$ 分别为不同功能区进口断面的人流流量和水质浓度.

对于往复流地区, 采用双向流计算公式, 具体如下 ${ }^{[11]}$ :

$$
W=\frac{A}{A+B} W_{\text {正 }}+\frac{B}{A+B} W_{\text {反 }}
$$

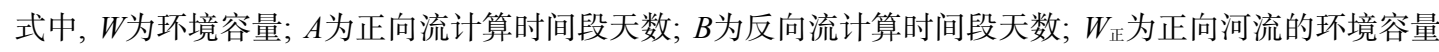




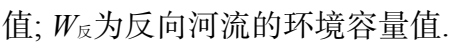

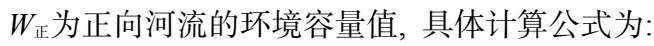

$$
W_{\text {正 }}=Q_{01}\left(C_{S}-C_{01}\right)+K_{1} V_{1} C_{S}
$$

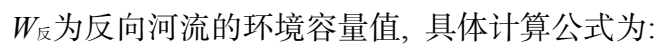

$$
W_{\text {反 }}=Q_{02}\left(C_{S}-C_{02}\right)+K_{1} V_{1} C_{S}
$$

1.2.2 河道控制方程 描述明渠一维非恒定流的基本方程为一维Saint-Venant方程组:

$$
\begin{gathered}
\frac{\partial Q}{\partial x}+B_{W} \frac{\partial Z}{\partial t}=q \\
\frac{\partial Q}{\partial t}+2 u \frac{\partial Q}{\partial x}+\left(g A-B u^{2}\right) \frac{\partial Z}{\partial x}-u^{2} \frac{\partial A}{\partial x}+g \frac{n^{2}|u| Q}{R^{4 / 3}}=0
\end{gathered}
$$

式中: $t$ 为时间坐标; $x$ 为空间坐标; $Q$ 为流量; $Z$ 为水位; $U$ 为断面平均流速; $n$ 为精率; $A$ 为过流断面面积; $B$ 为 主流断面宽度; $B_{W}$ 为水面宽度(包括主流宽度 $B$ 及仅起调蓄作用的附加宽度); $R$ 为水力半径; $q$ 为旁侧人流 流量.

方程的求解: 三级联合解法求解平原河网水力特性的基本思路可概括为: “单一河道一连接节点一单 一河道”. 即先将各单一河道划分为若干计算断面, 在计算断面上对Saint-Venant 方程组进行有限差分运 算, 得单一河道方程一一即以各断面水位及流量为自变量的差分方程组; 然后根据节点连接条件辅以边 界条件形成封闭的各节点水位方程，求解此方程组得各节点水位，再将各节点水位回代至单一河道方程， 最终求得各单一河道各断面水位及流量.

1.2.3 削减量计算:

$$
X=P-W
$$

式中: $X$ 为污染物削减量 $(\mathrm{t} / \mathrm{a}) ; P$ 为污染物人河量 $(\mathrm{t} / \mathrm{a}) ; W$ 为环境容量 $(\mathrm{t} / \mathrm{a})$. 污染物人河量可由不同污染源排 放量和人河系数计算获得. 污染源排放量根据污染源调查确定, 人河系数的取值根据已有研究成果确定.

\section{2 结果和讨论}

\section{1 计算条件的确定}

2.1.1 水环境功能目标确定 在水资源开发利用区域内, 按给定的水质目标和设计水量、水质条件, 水域 能纳污染物的最大量, 按照水环境功能区上下边界、监测断面设置, 选取最有代表性的监测断面, 将一个 功能区内可设多个监测断面来控制功能区的水质, 作为水环境容量计算的约束条件. 以水环境功能区不 同断面内相应环境质量标准类别的上限值为水质目标值. 水环境功能区相应环境质量标准具体落实于相 应的监控断面，断面达标即意味着水环境功能区水质达标. 根据近期、远期规划目标，确定漕桥河、武宜 运河 2012 年和 2020 年水环境功能目标分别为III和IV类水质标准.

2.1.2 典型年选取 选用太湖流域丹阳、茅东、赵村、溧阳、宜兴、常州、陈墅等 40 个雨量站 1954-2005 年共 52 年的年降水量资料，进行频率分析，得 $90 \%$ 保证率的典型年为 1971 年. 太湖模型计算的边界条件 分为长江沿线、宜溧山区、太湖边界等，由于区域计算边界水文边界条件的缺失，通过概化太湖流域河 网模型.

2.1.3 设计水文条件的确定 典型年中设计月份具体的选取方法是: 在每个水利分区中找出具有一定空间 代表性的流量站或水位站作为各水利分区的代表站，根据代表站实测资料统计得出最枯月均流量或最低 月均水位所在的月份，并以此水位来作为太湖流域低方案的水量(水深描述). 若该水利分区中有代表性 较好的流量站时, 则选择该流量站在 1971 年的最枯流量出现的月份作为设计月份; 若该水利分区中没有 代表性较好的流量站时，则选择该水利分区中代表性较好的水位站在 1971 年中最低水位出现的月份作 为设计月份. 无锡选取 1971 年 2 月作为设计月份. 采用太湖流域河网水量模型进行太湖流域河道设计水 文条件的计算. 水量模型中采用两类边界条件, 第一类是沿长江、杭州湾的潮位，选取 1971 年( $90 \%$ 保证 率的水情)长江至杭州湾的镇江、江阴、天生港、徐六泾、吴淞口、芦潮港、金山咀、乍浦、澉浦及盐官 等国家潮位站的潮位. 第二类是全流域降雨和蒸发资料.

计算工情指 1997 年已完成的水利工程及疏浚的河道状况. 此时, 望虞河已全线贯通, 太浦河泉站工 
程已竣工, 长江及杭州湾的其它各闸主要作用是为当地的防洪排涝及供水服务. 闸门的启闭根据当地水 位决定，尽量维持当地水位在适宜水位范围内. 当地水位超过适宜水位，开闸向长江或杭州湾排水. 低 于适宜水位时, 开闸从长江引水. 根据建立的太湖流域大型河网模型确定研究区域水文设计条件.

根据不同水利分区在典型年中选取设计月份，以月均最枯流量或月均最低水位作为典型年中设计月 份选取的依据. 太湖流域江苏区域划分为 4 个水利分区，分别为: 湖西区、阳澄区、澄锡虞区和淀泖区. 2.1.4 降解参数的确定 污染物的生物降解、沉降和其他物化过程, 可概括为污染物综合降解系数, 用实 测资料反推法计算污染物降解系数, 首先要选择河段, 分析上、下断面水质监测资料, 其次分析确定河段 平均流速, 用水质模型计算污染物降解系数, 第三采用临近时段水质监测资料验证计算结果, 确定污染 物降解系数. 河段选择时, 为减少随机因素对计算结果的影响, 应尽量选择没有排污口、支流口的河段作 为计算河段, 这样可以排除对水质监测结果的影响.

$$
K=\left(\ln C_{1}-\ln C_{2}\right) u / L
$$

式中: $K$ 为降解参数; $C_{1} 、 C_{2}$ 分别为河段上、下断面污染物浓度; $L$ 为上下断面距离; $u$ 为流速.

2.1.5 模型参数的率定 水量计算的目的是为水质计算提供水量数据，率定的目标主要考虑过程线的趋 势，没有对最高水位、流量或最低水位、流量刻意追求. 水位率定：选取江苏太湖流域 4 个代表水位站 1995 年和 1996 年的实测资料用于率定, 1995 年资料计算水位与实测值相当吻合, 1996 资料年流域内大 部分地区计算与实测水位吻合. 计算与实测最高水位误差小于 $20 \mathrm{~cm}$ 的比例超过 $70 \%$ (图 2a). 流量率定： 选取江苏太湖流域 7 个代表性断面 1995 年的实测资料用于率定流量, 计算的流量量级及趋势与实测值 一致. 由于流量站大多分布在太湖四周, 受太湖水位(风浪雍高)影响较大, 表现在实测流量过程线锯齿形 波动. 而模拟计算时, 太湖作边界条件处理, 因此沿太湖四周河道流量变化比较平滑. 1996 年资料用于江 苏太湖流域模型检验的流量站为 14 个，拟合程度与率定时一致见图 $2 \mathrm{~b}$. 水位及流量的计算结果与实测值 验证对比可知, 两者均吻合较好, 因此所建立的太湖流域河网水量模型, 能较准确地模拟该流域水流流 态. 根据模型计算值和实测值的对比计算，率定得到的太湖流域河道精率值在 0.015 至 0.022 之间.

\section{2 漕桥河水环境容量计算}

根据水环境功能目标原则及确定的水文设计条件, 计算不同规划年化学需氧量、氨氮、总磷环境容 量计算成果详见表 1 , 由于 $90 \%$ 保证率下最枯月流量均出现在冬季枯水期, 故在污染物综合降解系数取冬 季枯水期的平均值. 根据漕桥河水系情况及不同河段的水质特征，将漕桥河小流域划分为4段进行水环 境容量的测算，分段控制污染物允许排放量能保证漕桥河小流域的全线水质达标. 设计水文、水质目标 条件下研究河段2012年化学需氧量、氨氮和总磷分别为1961.71、97.41和8.83t/a; 2020年化学需氧量、氨 氮和总磷分别为 $1309.05 、 64.94$ 和 $5.89 \mathrm{t} / \mathrm{a}$.

在水环境容量模型计算的基础上，结合流域规划、上下游关系、水质评价和污染源调查结果、混合 区范围等因素，进行合理性分析，分析可利用的水环境容量，应结合水环境功能区水质评价和污染源调

表 1 漕桥河化学需氧量、氨氮和总磷环境容量(90\%保证率)计算成果

Tab.1 Water environmental capacities of chemical oxygen demand, ammonia nitrogen and total phosphorus of Caoqiao River in different types of years

\begin{tabular}{lcccccccc}
\hline \multirow{2}{*}{ 河流名称 } & \multicolumn{3}{c}{2012 年 } & & \multicolumn{3}{c}{2020 年 } \\
\cline { 2 - 3 } & & 化学需氧量 $(\mathrm{t} / \mathrm{a})$ & 氨氮 $(\mathrm{t} / \mathrm{a})$ & 总磷 $(\mathrm{t} / \mathrm{a})$ & & 化学需氧量 $(\mathrm{t} / \mathrm{a})$ & 氨氮 $(\mathrm{t} / \mathrm{a})$ & 总磷 $(\mathrm{t} / \mathrm{a})$ \\
\hline 漕桥河 & 1961.71 & 97.41 & 8.83 & & 1309.05 & 64.94 & 5.89 \\
黄土桥上游段 & 857.68 & 42.59 & 3.86 & & 572.33 & 28.39 & 2.58 \\
黄土桥-漕桥段 & 501.83 & 24.92 & 2.26 & & 334.87 & 16.61 & 1.51 \\
漕桥-风沟浜段 & 228.11 & 11.33 & 1.03 & & 152.22 & 7.55 & 0.68 \\
风沟浜-渎边桥段 & 374.09 & 18.58 & 1.68 & & 249.63 & 12.38 & 1.12 \\
\hline
\end{tabular}



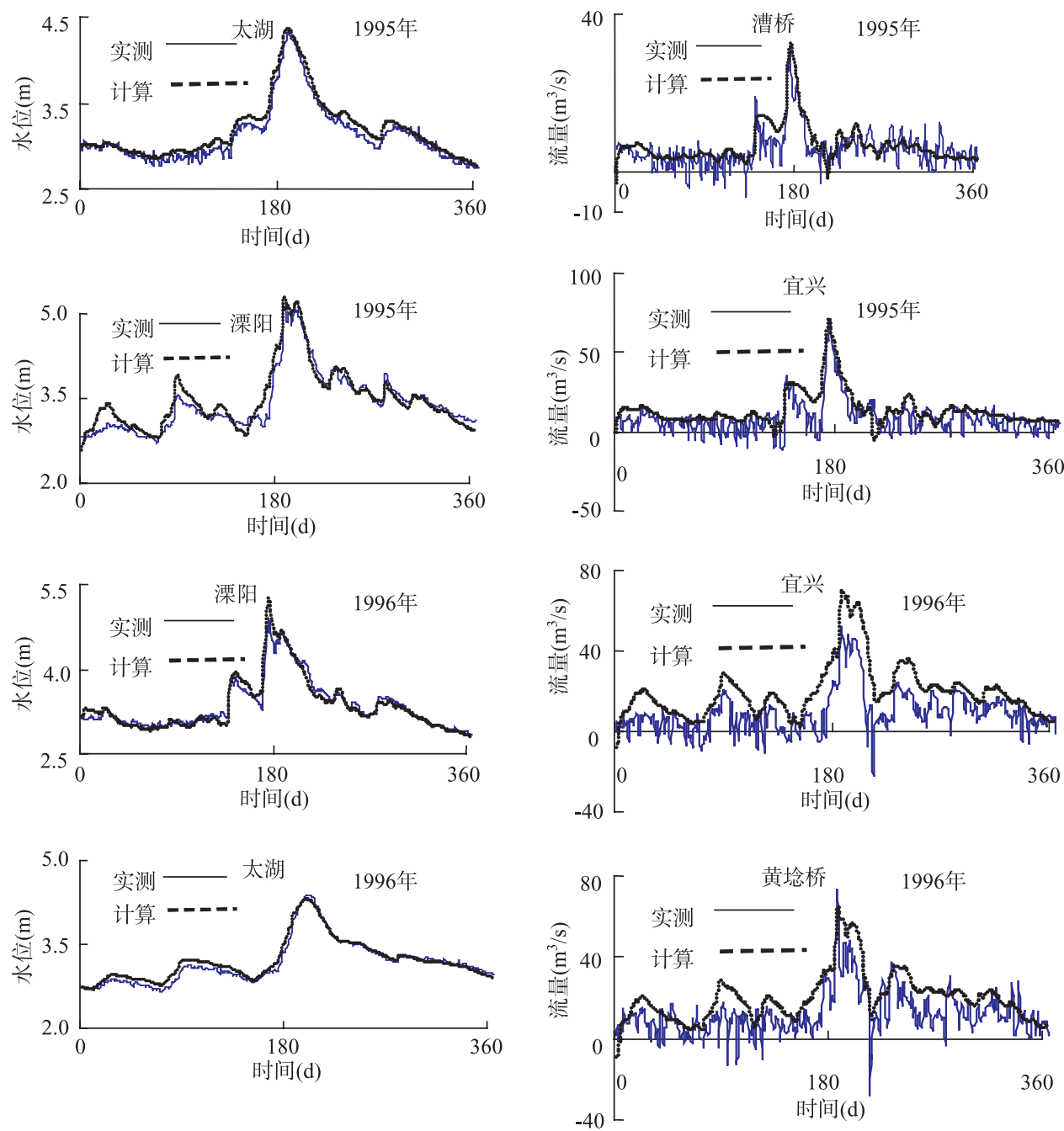

图 21995 年和 1996 年部分断面实测及计算水位率定对比(a)和流量验证(b)

Fig.2 Comparison of measured and calculated water level(a) and discharge(b) of part-section in 1995 and 1996

查分析，建立污染源与水质目标之间的输人响应关系，进行参数的校核和反馈调整，核定控制单元内允 许纳污量. 本次计算得到2012年化学需氧量的环境容量为 $1961.71 \mathrm{t}$, 实际人河量为 $1974.83 \mathrm{t}$, 氨氮的环境 容量为 $97.41 \mathrm{t}$, 实际人河量为 $325.65 \mathrm{t}$, 实际人河量超过水环境容量, 由水质评价结果可知: 目前漕桥河现 状水质化学需氧量和氨氮总体超标, 由此可知, 沿河水环境容量、污染物人河量与水质现状基本吻合, 说 明本次水环境容量的计算基本合理.

水环境容量和排放削减量的估算是总量控制的基础，而水质目标和估算模型的确定是水环境容量和 排放削减量估算的关键，漕桥河水环境功能区要求 2012 年为IV类水质，2020年为III类水质. 根据河道水 环境容量计算结果及目前各河道的现状纳污量，按照恢复河道水质，控制河道纳污量的原则，由公式1-8 计算得各水平年研究河网区污染物削减量, 结果见表 2 . 


\section{3 重点工程对削减量贡献分析}

重点组织实施五大类工程，共49个工程项目，总投资约 8.85 亿元. 其中宜兴 29 项，总投资约 5.74 亿元; 武进20项，总投资约3.11亿元.

（1）点源污染治理项目. 共计点源污染治理项目7项：完成宜兴市42个工业企业人河排污口封堵，48家 污染严重工业企业实行关停并转, 21家企业清洁生产审核和ISO14001认证, 20家工业企业提标治理工程. 武 进区57家化工企业关停并转, 关闭 8 家粮食加工企业聋糠发电, 以及4家企业提标改造和预处理接管工程.

(2) 城镇污水处理和垃圾处理处置项目. 共计实施城镇污水处理项目 16项, 其中，提标改造现有污水 处理厂工程5项，新(扩)建污水处理厂工程5项，管网工程建设6项，垃圾处理处置项目3项.

(3) 面源污染治理项目. 共计实施面源污染治理16项，其中，种植业清洁生产项目7项，畜禽养殖废 弃物处理利用工程5项，水产清洁养殖项目2项，分散农户污染治理2项.

（4）河道综合整治工程. 实施道综合整治工程4项，包括：宜兴市漕桥河主河道清淤工程、漕桥河支浜 清淤工程，武进区漕桥片区河网沟通、河道疏浚和截污工程、张仙浜清水工程.

(5) 生态修复工程. 实施生态修复工程 3 项：包括宜兴市人湖口生态堤岸修复工程、河岸带植被修复 工程，以及百渎港入湖口内湖净化系统工程中宜兴29项.

表 2 河网区污染物人河量及削减量计算成果表

Tab.2 The quantity of pollutants discharge to rivers and reduction in river network

\begin{tabular}{|c|c|c|c|c|c|c|}
\hline \multirow[b]{2}{*}{ 区域 } & \multicolumn{3}{|c|}{2012 年 } & \multicolumn{3}{|c|}{2020 年 } \\
\hline & $\begin{array}{c}\text { 化学需氧量 } \\
\text { (t/a) }\end{array}$ & $\begin{array}{l}\text { 氨氮 } \\
(t / a)\end{array}$ & $\begin{array}{l}\text { 总磷 } \\
(\mathrm{t} / \mathrm{a})\end{array}$ & $\begin{array}{c}\text { 化学需氧量 } \\
(t / a)\end{array}$ & $\begin{array}{l}\text { 氨氮 } \\
(t / a)\end{array}$ & $\begin{array}{l}\text { 总磷 } \\
(\mathrm{t} / \mathrm{a})\end{array}$ \\
\hline 漕桥河污染物人河量 & 1974.83 & 325.65 & 24.52 & 2402.76 & 396.22 & 29.84 \\
\hline 其中：黄土桥上游段 & 704.53 & 103.56 & 8.75 & 857.19 & 126.00 & 10.65 \\
\hline 黄土桥-漕桥 & 375.40 & 118.68 & 5.59 & 456.75 & 144.40 & 6.81 \\
\hline 漕桥-凤沟浜 & 650.84 & 57.56 & 6.65 & 791.87 & 70.04 & 8.09 \\
\hline 凤沟浜-渎边公路桥 & 244.07 & 45.84 & 3.53 & 296.95 & 55.78 & 4.29 \\
\hline 漕桥河污染物削减量 & 311.22 & 228.24 & 15.69 & 1093.71 & 331.28 & 23.95 \\
\hline 其中: 黄土桥上游段 & 0 & 61.84 & 4.97 & 296.60 & 98.19 & 8.13 \\
\hline 黄土桥-漕桥 & 0 & 94.05 & 3.36 & 125.76 & 127.98 & 5.32 \\
\hline 漕桥-凤沟浜 & 311.22 & 40.70 & 5.12 & 565.24 & 58.80 & 7.07 \\
\hline 凤沟浜-渎边公路桥 & 0 & 31.64 & 2.24 & 106.11 & 46.31 & 3.43 \\
\hline 漕桥河污染物削减率 & $15.8 \%$ & $70.1 \%$ & $64.0 \%$ & $45.5 \%$ & $83.6 \%$ & $80.3 \%$ \\
\hline
\end{tabular}

研究区近期需要削减的污染物量分别为化学需氧量 $734.8 \mathrm{t} / \mathrm{a}$ 、氨氮 $228.2 \mathrm{t} / \mathrm{a}$ 和总磷 $15.7 \mathrm{t} / \mathrm{a}$; 近期通过重 点项目的建设，可削减化学需氧量 $1584.1 \mathrm{t} / \mathrm{a}$ 、氨氮 $298.9 \mathrm{t} / \mathrm{a}$ 和总磷 $50.7 \mathrm{t} / \mathrm{a}$, 满足削减量的需要. 研究区远期 需要削减的污染物量分别为化学需氧量 $1202.8 \mathrm{t} / \mathrm{a}$ 、氨氮 $331.3 \mathrm{t} / \mathrm{a}$ 和总磷 $24.0 \mathrm{t} / \mathrm{a}$; 远期通过重点项目的建设, 可削减化学需氧量 $1636.5 \mathrm{t} / \mathrm{a}$ 、氨氮 $361.4 \mathrm{t} / \mathrm{a}$ 和总磷 $27.0 \mathrm{t} / \mathrm{a}$, 满足削减量的需要(表3). 经测算, 漕桥河达到 $\mathrm{V}$ 类水水质标准需要削减氨氮 $183.2 \mathrm{t} / \mathrm{a}$ 、总磷 $11.2 \mathrm{t} / \mathrm{a}$. 计划在 2008 年底前完成的重点工程项目主要是污水集 中处理厂提标改造、工业污染源整治和农业面源治理工程，以及部分河道清淤和生态修复项目，如以上 工程项目按计划完成，预计可以满足污染物总量削减目标，使漕桥河水质在2008年底基本达到 $\mathrm{V}$ 类水水 质标准要求. 
表 3 研究区污染物削减能力综合分析

Tab.3 The capacity for pollutants reduction analysis in the study area

\begin{tabular}{|c|c|c|c|c|c|}
\hline 水平年 & \multicolumn{2}{|l|}{ 污染物 } & 化学需氧量(t/a) & 氨氮(t/a) & 总磷(t/a) \\
\hline 2007年 & \multicolumn{2}{|c|}{ 基准年排放量 } & 1550.0 & 255.6 & 19.3 \\
\hline \multirow[t]{9}{*}{ 2012年 } & \multicolumn{2}{|c|}{ 预测总排放量 } & 1974.8 & 325.7 & 24.5 \\
\hline & \multicolumn{2}{|c|}{ 允许排放量 } & $1240^{1)}$ & 97.4 & 8.8 \\
\hline & \multicolumn{2}{|c|}{ 需要削减量 } & 734.8 & 228.2 & 15.7 \\
\hline & \multirow{6}{*}{ 削减能力 } & 点源污染治理项目 & 334.4 & 58.8 & 4.3 \\
\hline & & 污水处理和垃圾处理项目 & 75.2 & 13.2 & 1.0 \\
\hline & & 面源污染治理项目 & 784.6 & 138.0 & 10.0 \\
\hline & & 河道综合整治工程 & 361.9 & 45.2 & 31.4 \\
\hline & & 生态修复工程 & 28.0 & 43.7 & 4.1 \\
\hline & & 合计 & 1584.1 & 298.9 & 50.7 \\
\hline \multirow[t]{6}{*}{ 2020年 } & \multirow{3}{*}{\multicolumn{2}{|c|}{$\begin{array}{l}\text { 预测总排放量 } \\
\text { 允许排放量 } \\
\text { 需要削减量 }\end{array}$}} & 2402.8 & 396.2 & 29.8 \\
\hline & & & 1200.0 & 64.9 & 5.9 \\
\hline & & & 1202.8 & 331.3 & 24.0 \\
\hline & \multirow[t]{3}{*}{ 削减能力 } & 污水处理和垃圾处理处置 & 1543.8 & 263.6 & 18.4 \\
\hline & & 生态修复工程 & 92.7 & 97.8 & 8.6 \\
\hline & & 合计 & 1636.5 & 361.4 & 27.0 \\
\hline
\end{tabular}

1)表示按照江苏省政府化学需氧量年度削减计划确定.

\section{3 结论}

(1)基于水质目标条件下的分段环境容量的计算结果与河道水质的响应关系较好，水环境容量达标基 本上可反映该水体的水质浓度达标，说明本次水环境容量的计算结果合理.

(2)根据确定的污染物削减量，提出河流污染分段控制和流域管理的水环境容量控制模式.

(3)重点工程可达到污染物总量削减目标, 漕桥河水质可满足功能区水质标准要求.

\section{4 参考文献}

[1] 胡国华, 赵沛伦, 王任翔. 黄河孟津一花园口河段水环境容量研究. 水资源保护, 2002, 18(1): 26-28.

[2] 李永军, 陈余道, 孙 涛. 地理信息模型方法初探河流环境容量——以漓江桂林市区段为例. 水科学进展, 2005, 16(2): 280-283.

[3] 黄玉凯. 水污染物排放总量控制的定量化过程与方法. 上海环境科学, 1990, 9(5): 2-4.

[4] 李如忠, 汪家权, 钱家忠. 区域水污染负荷分配Delphi-AHP法. 哈尔滨工业大学学报, 2005, 37(1): 84-88.

[5] 徐贵泉, 褚君达, 吴祖扬等. 感潮河网水环境容量数值计算. 环境科学学报, 2000, 20(3): 263-268.

[6] 夏 青, 孙 艳, 贺 珍等. 水污染物总量控制实用计算方法概要. 环境科学研究, 1989(专辑): 120-126.

[7] 水利部水政水资源司. 水资源保护管理基础. 北京：中国水利水电出版社, 1996: 104-108.

[8] 陈兴伟, 刘梅冰. 感潮河道水环境容量理论及计算的若干问题. 福建师范大学学报(自然科学版), 2006, 22(2): 104-107.

[9] 储君达, 何惠慈. 河网水质模型及其数值模拟. 河海大学学报(自然科学版), 1992, (1): 16-22.

[10] 罗 缙, 逢 勇, 罗清吉等. 太湖流域平原河网区往复流河道水环境容量研究. 河海大学学报(自然科学版), 2004, 32(2): 144-146.

[11] 姚国金, 逢 勇, 刘智森. 水环境容量计算中不均匀系数求解方法探讨. 人民珠江, 2000, (4): 47-50. 